\title{
Association of PPAR $\gamma 2$ gene variant Prol 2Ala polymorphism with hypertension and obesity in the aboriginal Qatari population known for being consanguineous
}

\author{
This article was published in the following Dove Press journal: \\ The Application of Clinical Genetics \\ 23 October 2013 \\ Number of times this article has been viewed
}

\begin{abstract}
Abdulbari Bener ${ }^{1,2}$
Sarah Darwish ${ }^{3}$

Abdulla OAA Al-Hamaq ${ }^{4}$

Ramzi M Mohammad ${ }^{5,6}$

Mohammad T Yousafzai'

'Department of Medical Statistics and Epidemiology, Hamad Medical Corporation, Department of Public Health, Weill Cornell Medical

College, Doha, Qatar; ${ }^{2}$ Department of Evidence for Population Health Unit, School of Epidemiology and Health Sciences, University of Manchester, Manchester, UK; ${ }^{3}$ Department of Endocrinology, Hamad General Hospital, Hamad Medical Corporation, Doha, Qatar; ${ }^{4}$ Qatar Diabetic Associations and Qatar Foundation, Doha, Qatar; ${ }^{5}$ Department of Oncology, Barbara Ann Karmanos Cancer Institute, Wayne State University, School of Medicine, MI, USA; ' Department of Medicine, Hamad Medical Corporation, Doha, Qatar
\end{abstract}

Aim: The aim of this study was to investigate the association of the Pro12Ala polymorphism of the human peroxisome proliferator-activated receptor gamma 2 (PPAR 2 ) gene with hypertension and obesity in a highly consanguineous aboriginal Qatari population.

Design: A cross-sectional survey conducted from January 2011-December 2012.

Setting: Primary health care clinics.

Subjects: A random sample of 1,528 Qatari male and female population older than 20 years of age.

Materials and methods: Data on age, sex, income, level of education, occupation status, body mass index, and blood pressure and lipid profile were obtained. The Pro12Ala in the PPAR $\gamma 2$ gene was detected on the LightCycler ${ }^{\circledR}$ using two specific probes: (Sensor [G] $5^{\prime}-\mathrm{CTC}$ CTA TTG ACG CAG AAA GCG-FL and PPAR Anchor 5' LC Red 640- TCC TTC ACT GAT ACA CTG TCT GCA AAC ATA TC-PH). Univariate and multivariate logistic regression were performed.

Result: Out of a total 1,528 participants, 220 were diagnosed with essential hypertension, and 420 were obese. Participants with consanguinity were significantly higher among hypertensive than normotensive $(41.9 \%$ versus $30.8 \% ; P=0.001)$. Altogether, more than three-fourths $(89 \%)$ of the participants had a wild genotype (Pro12Pro), 9.8\% were heterozygous with Pro12Ala, and only $1.2 \%$ was homozygous with the Ala12Ala genotype. The frequency of the Pro allele was $94.5 \%$ in normotensive versus $90.5 \%$ in hypertensive, while the distribution of the Ala allele was $5.5 \%$ in normotensive versus $9.5 \%$ in the hypertensive group ( $P=0.001)$. The odds of hypertension were 1.7 times higher among the participants with the Ala allele as compared to those with the Pro, while adjusting for other potential confounders (adjusted odds ratio 1.69; $95 \%$ confidence interval $1.12-2.55 ; P=0.012)$. There was no association between the PPAR $\gamma 2 \mathrm{Ala}$ allele and obesity $(P=0.740)$.

Conclusion: The current study revealed an association between the PPAR $\gamma 2$ Ala allele and hypertension in Qatar's population. On the other hand, this study found no association between the Ala allele and obesity.

Keywords: hypertension, PPAR $\gamma 2$ gene, consanguinity, obesity, Pro12Ala polymorphism

\section{Introduction}

Peroxisome proliferator-activated receptors (PPARs) are members of the type II nuclear hormone receptor superfamily. They were first discovered in 1990 by Issemann and Green. ${ }^{1}$ There are three subtypes of PPARs - PPAR $\alpha, \beta$, and $\gamma$. Among them, the $P P A R \gamma$ is activated by certain fatty acids, prostanoids, and the insulin-sensitizing 
antidiabetic agent, the thiazolidinedione. ${ }^{2}$ Upon activation, PPAR $\gamma$ heterodimerizes with the retinoid $\mathrm{X}$ receptor and binds to the PPAR responsive element of DNA to promote the transcription of target genes. ${ }^{3}$ The human PPAR $\gamma$ gene is located on chromosome $3 \mathrm{p} 25$ and produces three different isoforms - PPAR $\gamma 1$, PPAR $\gamma 2$, and PPAR $\gamma 3$ - as a result of alternative mRNA splicing. ${ }^{4}$ The PPAR $\gamma 2$ isoform is mainly found in adipose tissue, and it plays a key role in regulating adipogenic differentiation and glucose homeostasis. ${ }^{5-6}$

The number of genetic variants in the PPAR $\gamma$ gene has been identified. The most common is the cytosine to guanine (CCA-to-GCA) missense mutation in codon 12 of exon B of the PPAR rgene, resulting in the change of the amino acid proline to alanine (Pro12Ala). The exon B is responsible for encoding the $\mathrm{NH}_{2}$-terminal amino acids that define the adipocyte-specific PPAR $\gamma 2$ isoform. Since the substitution of alanine for proline is nonconservative and causes a significant change in protein structure, it has been suggested that it may alter the function of PPAR $\gamma 2$, thereby leading to a Pro12Ala variant with a lower affinity for the response element and a lower capacity for activating target genes by about $50 \%$. $^{7}$ Furthermore, individuals with the variant may be at an increased genetic risk for obesity, insulin resistance, diabetes mellitus, and hypertension. ${ }^{8-11}$

A number of studies have been conducted in different populations to elucidate the association of the Ala12 variant with obesity ${ }^{11-14}$ and hypertension. ${ }^{15-17}$ Nonetheless, results of these studies are not consistent, which could be partly attributed to the insufficient power of the studies, and/or ethnic and environmental variations, suggesting a gene-environment interaction. Furthermore, the practice of consanguineous marriages is very high in Qatar (54\%), ${ }^{18,19}$ resulting in a profound impact on the genetic structure of the Qatari population ${ }^{20}$ and suggesting that risk factors identified through the European genome-wide association studies might not be valid in this population. Also, Qatar has observed rapid urbanization and lifestyle changes during the last decade, resulting in a dramatic increase in the prevalence of hypertension and obesity. ${ }^{21-22}$

To achieve a definite conclusion about the association of the Pro12Ala polymorphism with obesity and hypertension in Qatar, the present study has recruited a large random sample of the highly consanguineous aboriginal Qatari population.

\section{Materials and methods}

A cross-sectional study was performed among the adult Qatari population over 20 years of age during the January 2011-December 2012 time period. The study protocol was approved by the Research Ethics Committee of the Hamad General Hospital, Hamad Medical Corporation. Written informed consent was obtained from all the participants before data collection. Participants were briefed about the study, and strict confidentiality of data was ensured.

\section{Sampling procedure}

A multistage, stratified cluster sampling experiment was designed, using the geographic administrative divisions of the primary health centers in Qatar that had approximately an equal population coverage. To secure a representative sample of the study population, sampling was stratified to obtain a proportional representation from both urban and semiurban areas. The sample size was determined by considering $25 \%{ }^{21}$ prevalence of hypertension among the general population in Qatar - assuming a 99\% confidence level, 95\% power, and considering $4 \%$ bound on error of estimation - the minimum sample size required to achieve the objective of this study was 2,182 subjects. Of the 22 primary health care centers available, 13 were selected at random (ten from urban and three semiurban). Finally, the subjects were systematically labeled 1-in-2, using standard sampling procedures. During the study period, 2,182 subjects were approached and 1,528 (70\%) consented to participate in the study.

\section{Questionnaire and data collection}

A well-designed and pilot-tested questionnaire was used to collect the data. The questionnaire was pilot-tested among 100 subjects before the initiation of the main survey. Necessary corrections and alterations were made, based on the pilot results. The first part of the questionnaire included information about sociodemographic and anthropometric characteristics, including age, sex, marital status, education level, occupation, height, weight, and parental consanguinity. The second part consisted of variables about comorbidities and lifestyle habits, such as smoking status and physical activity. The third part of the questionnaire was based on systolic and diastolic blood pressures, blood lipid profile, blood glucose, glycosylated hemoglobin (HbA1C), and Pro12Ala polymorphism.

Face-to-face interviews were conducted by trained nurses to obtain information regarding sociodemographic characteristics, consanguinity, and history of comorbidities, physical activity, and smoking habit.

Information regarding consanguinity was obtained by asking the question: "are your parents related to each other?" If the answer was "Yes," then further questions were asked; are the parents "first cousins" or "second 
cousins"? If the parents of the participant were either first or second cousins to each other, they were defined as "consanguineous."

Smoking status was categorized as "never smoker," "past smoker," and "current smoker." Information on physical activity was obtained subjectively by asking questions regarding any activity that caused light perspiration or a slight-to-moderate increase in breathing or heart rate for at least 60 minutes a week (vigorous physical activity), 30 minutes a week (moderate physical activity), and less than 30 minutes a week (mild physical activity).

Information about the lipid profile (total cholesterol, high-density lipoprotein [HDL] cholesterol, low-density lipoprotein [LDL] cholesterol, and triglycerides) was retrieved from the medical records. The laboratory reference values for total cholesterol were: $<5.17 \mathrm{mmol} / \mathrm{L}$ as desirable, 5.17-6.18 $\mathrm{mmol} / \mathrm{L}$ as borderline high, and above $6.18 \mathrm{mmol} / \mathrm{L}$ as high; LDL cholesterol $<3.36 \mathrm{mmol} / \mathrm{L}$ as desirable, $3.36-4.11$ as borderline, and $>4.12$ as high risk; HDL cholesterol $<1.0 \mathrm{mmol} / \mathrm{L}$ as low; and triglycerides $<1.7$ as normal, 1.7-2.2 as borderline, and 2.2-5.6 as high.

\section{Physical examination and measurements}

Physical examination and measurements were performed by a trained nurse. Height was measured in centimeters using a height scale (Seca GmbH and Co, KG, Hamburg, Germany) while the subject was standing barefooted and with normal, straight posture. Male subjects were requested to remove their head cover (Igaal and Guttra) as their weight was measured in kilograms with a weight scale (Seca). The subjects were asked to remove any objects from their pockets and to stand on the weight scale barefooted with light clothing. Body mass index (BMI) was calculated as the ratio of weight (kilograms) to the square of height (meters). ${ }^{23}$ Obesity and overweight were classified according to World Health Organization criteria. ${ }^{24} \mathrm{~A}$ person was considered obese if his/her BMI value was $\geq 30 \mathrm{~kg} / \mathrm{m}^{2}$ and was considered overweight if the BMI $\geq 25 \mathrm{~kg} / \mathrm{m}^{2}$ and $<30 \mathrm{~kg} / \mathrm{m}^{2}$.

Blood pressure measurements were also carried out by trained nurses. Two readings of the systolic and diastolic blood pressure were taken from the subject's left arm while seated with his/her arm at heart level, using a standard zero mercury sphygmomanometer after at least 10-15 minutes of rest. The average of the two readings was obtained for analysis. Hypertension was defined according to the seventh report of the US National Heart, Lung, and Blood Institute Joint National Committee on Prevention, Detection, Evaluation, and Treatment of High Blood Pressure. ${ }^{25}$ The participant was considered hypertensive if the systolic blood pressure was $\geq 140 \mathrm{mmHg}$ and/or the diastolic blood pressure was $\geq 90 \mathrm{mmHg}$, or he/she was already taking medication for essential hypertension.

\section{Laboratory measurement and procedures}

Blood samples were collected via venipuncture into vacutainer ethylenediaminetetraacetic acid tubes and used for manual DNA purification using QiaAmp mini DNA kits (QIAGEN, Venlo, Netherlands). Random glucose values were determined using the OneTouch ${ }^{\circledR}$ SureStep Kit (LifeScan, Inc., Milpitas, CA, USA). $\mathrm{HbA}_{1 \mathrm{c}}$ was analyzed using highperformance liquid chromatography.

The single nucleotide polymorphism detection protocol was based on a procedure in earlier studies by Ghoussaini et $\mathrm{al}^{11}$ and Badii et al. ${ }^{14}$ It consisted of an amplification step by polymerase chain reaction (PCR) followed by the mutation analysis of the PCR product via real-time PCR. The PCR primer set consisted of: PGEx1F 5'-AAT AGG ACA GTG CCA GCC-3' and PGEx1R 5'-TAC ATA AAT GCC CCC ACG-3'. The reaction was performed in a final volume of $25 \mu \mathrm{L}$ and contained: $1 \times$ GeneAmp $^{\circledR}$ PCR Gold Buffer (Life Technologies, Grand Island, NY, USA); $2.5 \mathrm{mM} \mathrm{MgCl}_{2}$, 1\% DMSO, $0.25 \mathrm{mM}$ each dNTP, two primers (PGEx1F: $4.3 \mathrm{nM}$ and PGEx1R 3.58 nM), 0.75U AmpliTaq Gold ${ }^{\circledR}$ DNA polymerase (Life Technologies), and 100-500 ng template DNA. The PCR consisted of an initial denaturation at $95^{\circ} \mathrm{C}$ for 12 minutes, followed by 35 cycles of denaturation at $95^{\circ} \mathrm{C}$ for 30 seconds, annealing at $58^{\circ} \mathrm{C}$ for 30 seconds, and elongation at $72^{\circ} \mathrm{C}$ for 30 seconds.

The Pro12Ala in the PPAR 22 gene was detected on the LightCycler $^{\circledR}$ (Roche Applied Science, Penzberg, Upper Bavaria, Germany) using two specific probes: (Sensor [G] 5'-CTC CTA TTG ACG CAG AAA GCG-FL and PPAR Anchor 5' LC Red 640-TCC TTC ACT GAT ACA CTG TCT GCA AAC ATA TC-PH). The melting temperature profiles were interpreted as follows: wild type $(\mathrm{CC}), 54^{\circ} \mathrm{C}$; mutant (GG), $60^{\circ} \mathrm{C}$; and heterozygous (CG), $54^{\circ} \mathrm{C}$ and $60^{\circ} \mathrm{C}$.

\section{Statistical analysis}

Data were analyzed using the Statistical Package for Social Sciences version 20 (IBM Corporation, Armonk, NY, USA) software. Continuous variables were tested for normality using histograms and the Kolmogorov-Smirnov test. The Student $t$-test was used to ascertain the significant difference between two means of a continuous variable. A chi-square test (twotailed) was performed to test for differences in the proportions of categorical variables between two or more groups. The 
significance-of-deviations of observed genotypic frequencies from those predicted by the Hardy-Weinberg equation were evaluated with chi-square tests between the hypertensive and normotensive groups and between the obese and nonobese groups. A multivariable logistic regressions analysis was used to determine the association of Pro12Ala with hypertension and obesity while adjusting for the potential confounders (age, sex, smoking status, physical activity, consanguinity, and the use of antihypertensive medication). Interaction between the consanguinity and the Pro12Ala polymorphism was assessed by including the interaction term in multivariable logistic regression models for obesity and hypertension; $P$-value was noted for significance. The level $P \leq 0.05$ was considered as the cut-off value for significance.

\section{Results}

Of a total 1,528 participants, 220 were diagnosed with essential hypertension and 420 were obese with a BMI $\geq 30$. The 45-60 age group was significantly higher among the hypertensive group when compared to the normotensive. On the contrary, the proportion of participants aged 30-45 years was significantly higher in the normotensive group when compared to the counterpart $(55.5 \%$ versus $45.8 \%$ and $13.2 \%$ versus $23.6 \%$, respectively; $P=0.004$ ). Participants aged $<30$ years and $>60$ years had similar distribution across the hypertensive and normotensive groups. Participants with consanguinity were significantly higher among hypertensive as compared to normotensive (41.9\% versus $30.8 \% ; P=0.001)$. Almost one-third of the hypertensive participants were obese with a BMI of $\geq 30$, as opposed to only one-fourth of the obese participants in the normotensive group (35.5\% versus $26.1 \%$; $P=0.014$ ). Only $18.6 \%$ of the hypertensive participants were involved in a moderate level of physical activity as compared to $30 \%$ in the normotensive group $(P<0.001)$. Almost $15 \%$ of the hypertensive participants were current smokers, as opposed to $9 \%$ among the normotensive $(P=0.018)$ (Table 1$)$.

Table 2 shows the distribution of blood pressure measurements, the blood lipid profile, and the blood glucose level between hypertensive and normotensive participants. The mean glucose level and the $\mathrm{HbA}_{1 \mathrm{c}}$ were significantly higher in the hypertensive group as compared to normotensives $(7.66 \pm 2.4$ versus $5.8 \pm 2.6 ; P<0.001$ and $7.09 \pm 2.1$ versus $5.43 \pm 2.2 ; P<0.001$, respectively). There were no statistically significant differences in terms of blood lipid parameters between the hypertensive and the normotensive group except total cholesterol, which was significantly higher in the hypertensive than the counterpart group
(5.46 \pm 1.0 versus $4.92 \pm 1.0 ; P=0.003)$. Almost $39 \%$ of the hypertensive group participants were diabetics; $12.7 \%$ had a previous stroke; $15.5 \%$, cardiovascular disease (CVD); $19.1 \%$, retinopathy; $15.9 \%$, nephropathy; and $14.1 \%$, neuropathy. The difference was statistically significant ( $P<0.001$, respectively), when compared to the normotensive population.

Table 3 shows the distribution of the PPAR $\gamma 2$ gene polymorphism across the hypertensive and normotensive categories. Altogether, more than three-fourths (89\%) of the participants had the wild genotype (Pro12Pro), and 9.8\% were heterozygous with Pro12Ala. Only 1.2\% was homozygous with the Ala12Ala genotype. The Pro12Pro genotype occurrence was significantly higher in the normotensive group as opposed to the hypertensive $(89.8 \%$ versus $84 \% ; P=0.003$, respectively). On the other hand, the proportion of the genotypes Pro12Ala and Ala12Ala was significantly higher in the hypertensive group as compared to the normotensive $(12.7 \%$ versus $9.3 \%$ and $3.2 \%$ versus $0.8 \%$, respectively).

The distribution of the PPAR $\gamma 2$ gene polymorphism across the obese and nonobese participants revealed no significant differences across all the three genotypes $(P=0.787)$. On the contrary, the distribution of both the genotypes' and the alleles' frequencies between hypertensive and normotensive was statistically significant. The frequency of the Pro allele was 0.945 in the normotensive group versus 0.905 in the hypertensive group. While the distribution of Ala allele was 0.055 in the normotensive group versus 0.095 in the hypertensive $(P=0.001$; odds ratio $=1.81 ; 95 \%$ confidence interval [CI] 1.24-2.63 for Ala allele as compared to Pro) (Table 4).

Table 5 presents predictors of hypertension, based on a multivariable logistic regression analysis. The odds of hypertension were 1.7 times higher among the participants with an Ala allele, as opposed to those with the wild type Pro allele when adjusted for other potential confounding factors, such as age, obesity, triglycerides, consanguinity, smoking, physical activity, and antihypertensive medication (adjusted odds ratio $1.69 ; 95 \% \mathrm{CI} 1.12-2.55 ; P=0.012$ ).

Table 6 shows a multivariable logistic regression analysis for obesity. The odds of obesity among the participants with the Ala allele were 0.94 , as opposed to those with the Pro allele when adjusted for potential confounders, but the association was not statistically significant (adjusted odds ratio $0.94 ; 95 \% \mathrm{CI} 0.65-1.35 ; P=0.740$ ).

Interaction between consanguinity and the Ala12 variant and its association with obesity and hypertension was found to be statistically insignificant and, hence, the interaction 
Table I Distribution of sociodemographic, lifestyle characteristics, and consanguinity across hypertensive and normotensive subjects in Qatar $(\mathrm{N}=\mathrm{I}, 528)$

\begin{tabular}{|c|c|c|c|c|}
\hline & $\begin{array}{l}\text { Total } \\
\mathrm{N}=1,528 \text { (\%) }\end{array}$ & $\begin{array}{l}\text { Hypertensive } \\
\mathrm{N}=220 \text { (\%) }\end{array}$ & $\begin{array}{l}\text { Normotensive } \\
\mathrm{N}=1,308 \text { (\%) }\end{array}$ & $P$-value \\
\hline Age in years (mean $\pm S D$ ) & $50.44 \pm 12.3$ & $51.10 \pm 11.1$ & $50.33 \pm 12.5$ & 0.390 \\
\hline \multicolumn{5}{|l|}{ Age (in years) } \\
\hline$<30$ & $100(6.5)$ & $13(5.9)$ & $87(6.7)$ & \multirow[t]{4}{*}{0.004} \\
\hline $30-44.99$ & $338(22.1)$ & $29(13.2)$ & $309(23.6)$ & \\
\hline $45-59.99$ & 721 (47.2) & $122(55.5)$ & $599(45.8)$ & \\
\hline 60 and above & $369(24.1)$ & $56(25.5)$ & $313(23.9)$ & \\
\hline Sex (male) & $718(47.0)$ & II 5 (52.3) & $603(46.1)$ & 0.090 \\
\hline \multicolumn{5}{|l|}{ Level of education } \\
\hline$<$ Secondary & $804(52.6)$ & $128(58.2)$ & $676(51.7)$ & \multirow[t]{2}{*}{0.074} \\
\hline Secondary and above & $724(47.4)$ & $92(41.8)$ & $632(48.3)$ & \\
\hline \multicolumn{5}{|l|}{ Occupation } \\
\hline Housewife & $477(3 \mid .2)$ & $86(39.1)$ & 391 (29.9) & \multirow[t]{6}{*}{0.004} \\
\hline Sedentary/professional & $390(25.5)$ & $50(22.7)$ & $340(26.0)$ & \\
\hline Manual & $317(20.7)$ & $38(17.3)$ & $279(21.3)$ & \\
\hline Businessmen & $136(8.9)$ & $26(11.8)$ & $110(8.4)$ & \\
\hline Army/police & 118 (7.7) & $16(7.3)$ & $102(7.8)$ & \\
\hline Clerk & $90(5.9)$ & $4(1.8)$ & $86(6.6)$ & \\
\hline \multicolumn{5}{|l|}{ Household income (QR) } \\
\hline$<10,000$ & $593(38.8)$ & $84(38.2)$ & $509(38.9)$ & \multirow[t]{3}{*}{0.039} \\
\hline $10,000-14,999$ & $554(36.3)$ & $94(42.7)$ & $460(35.2)$ & \\
\hline 15,000 and above & $381(24.9)$ & $42(19.1)$ & $339(25.9)$ & \\
\hline Consanguinity* & $495(32.4)$ & $92(41.9)$ & $403(30.8)$ & 0.001 \\
\hline \multicolumn{5}{|l|}{ BMI } \\
\hline$<25$ & $496(32.5)$ & $67(30.5)$ & $429(32.8)$ & \multirow[t]{3}{*}{0.014} \\
\hline $25-29.9$ & $612(40.1)$ & $75(34.1)$ & $537(4 I . I)$ & \\
\hline 30 and above & $420(27.5)$ & $78(35.5)$ & $342(26.1)$ & \\
\hline \multicolumn{5}{|l|}{ Physical activity levels* } \\
\hline Vigorous & $433(28.7)$ & $53(24.1)$ & $380(29.5)$ & 0.104 \\
\hline Moderate & $432(28.6)$ & $41(18.6)$ & $391(30.3)$ & $<0.001$ \\
\hline Mild & $363(24.0)$ & $59(26.8)$ & $304(23.6)$ & 0.297 \\
\hline \multicolumn{5}{|l|}{ Smoking status } \\
\hline Never & $\mathrm{I}, 274(83.3)$ & $176(80.0)$ & I,098 (83.9) & \multirow[t]{3}{*}{0.018} \\
\hline Past smoker & $108(7.1)$ & $12(5.5)$ & $96(7.4)$ & \\
\hline Current smoker & $146(9.6)$ & $32(14.5)$ & II 4 (8.7) & \\
\hline
\end{tabular}

Notes: *Represents only positive responses. Numbers do not add up to 100\% (3.64QR = US\$1.00).

Abbreviations: SD, standard deviation; QR, Qatari Rial; BMI, body mass index.

term was dropped out of the multivariable regression analysis (data not shown).

\section{Discussion}

We determined the frequency of the proline-to-alanine substitution of the human PPAR $\gamma 2$ gene and investigated its association with hypertension and obesity in Qatar's highly consanguineous population. In this study, the frequency of the Ala12 allele was 0.061 . While the frequency of Ala12 allele remained similar among both obese and nonobese subjects (0.061), it was significantly higher among hypertensive than in the normotensive population ( 0.095 versus 0.055$)$. This study found a significant association between the Ala12 variant of the PPAR 2 gene and hypertension among the highly consanguineous Qatari population. However, no association was detected between the Ala12 variant and obesity.

The allelic frequency of the Pro12Ala polymorphism varies among different ethnic communities. The frequency of the Ala12 allele is generally higher among Caucasians $(0.11-0.13)^{11,26}$ than the other ethnicities: Qatari's aboriginal population, $0.057 ; ;^{14}$ Korean, $0.058 ;{ }^{16}$ Japanese, $0.041 ;{ }^{27}$ Taiwanese, $0.04 ;{ }^{28}$ Chinese, $0.036 ;{ }^{29}$ and Javanese Indonesian, $0.017 .{ }^{12}$ Our finding of the Ala12 allelic frequency (0.061) is slightly higher than the East Asian ethnicities and much lower than the Caucasian populations. Nevertheless, our finding is consistent with the previous report about the aboriginal Qatari population. ${ }^{14}$ Literature regarding the Ala12 allelic frequency among the hypertensive and normo- 
Table 2 Distribution of comorbidities, blood pressure measurements, biochemical parameters across hypertensive and normotensive in Qatar $(\mathrm{N}=1,528)$

\begin{tabular}{|c|c|c|c|c|}
\hline & Total & Hypertensive & Normotensive & $P$-value \\
\hline & $\frac{N=1,528}{\text { Mean } \pm \text { SD }}$ & $\frac{\mathbf{N}=220}{\text { Mean } \pm \text { SD }}$ & $\frac{N=1,308}{\text { Mean } \pm \text { SD }}$ & \\
\hline Mean systolic BP (mmHg) & $131.44 \pm 16.9$ & $150.10 \pm 14.2$ & $128.28 \pm 15.2$ & $<0.001$ \\
\hline Mean diastolic BP $(\mathrm{mmHg})$ & $80.32 \pm 8.8$ & $94.17 \pm 5.5$ & $77.99 \pm 6.9$ & $<0.001$ \\
\hline \multicolumn{5}{|l|}{ Serum lipid profile } \\
\hline Total cholesterol (mmol/L) & $5.19 \pm 1.0$ & $5.46 \pm 1.0$ & $4.92 \pm 1.0$ & 0.003 \\
\hline LDL-C (mmol/L) & $2.90 \pm 0.9$ & $2.90 \pm 1.0$ & $2.89 \pm 0.9$ & 0.972 \\
\hline $\mathrm{HDL}-\mathrm{C}(\mathrm{mmol} / \mathrm{L})$ & $1.28 \pm 0.3$ & $1.30 \pm 0.3$ & $1.28 \pm 0.3$ & 0.513 \\
\hline $\mathrm{TG}(\mathrm{mmol} / \mathrm{L})$ & $1.62 \pm 0.8$ & $1.67 \pm 0.7$ & $1.62 \pm 0.8$ & 0.308 \\
\hline Blood glucose (mmol/L) & $6.48 \pm 2.6$ & $7.66 \pm 2.4$ & $5.80 \pm 2.6$ & $<0.001$ \\
\hline \multirow[t]{2}{*}{$\mathrm{HbA}_{\mathrm{Ic}}$} & $6.35 \pm 2.2$ & $7.09 \pm 2.1$ & $5.43 \pm 2.2$ & $<0.001$ \\
\hline & $\mathbf{N}(\%)$ & $\mathbf{N}(\%)$ & N (\%) & \\
\hline \multicolumn{5}{|l|}{ Comorbidities* } \\
\hline Diabetes & $359(23.5)$ & $86(39.1)$ & $273(20.8)$ & $<0.001$ \\
\hline Stroke & $96(6.3)$ & $28(12.7)$ & $68(5.2)$ & $<0.001$ \\
\hline CVD & $98(6.4)$ & $34(15.5)$ & $64(4.9)$ & $<0.001$ \\
\hline Retinopathy & $15 \mid(9.9)$ & $42(19.1)$ & $109(8.3)$ & $<0.00$ I \\
\hline Nephropathy & $|2|(7.9)$ & $35(15.9)$ & $86(6.6)$ & $<0.001$ \\
\hline Neuropathy & $123(8.1)$ & $31(14.1)$ & $92(7.0)$ & $<0.001$ \\
\hline
\end{tabular}

Notes: *Represents only positive responses. Numbers do not add up to $100 \%$.

Abbreviations: BP, blood pressure; SD, standard deviation; HDL-C, high-density lipoprotein cholesterol; LDL-C, low-density lipoprotein cholesterol; HbA hemoglobin; CVD, cardiovascular disease; TG, triglycerides.

tensive and/or obese and nonobese population separately is scarce. However, a study among Korean women ${ }^{16}$ reported a similar frequency of the Ala12 allele between the obese and nonobese subjects and was higher among the hypertensive than the normotensive subjects, which is consistent with our findings. Variations in the allelic frequency of the Pro12Ala polymorphism across different ethnicities and regions could be attributed to genetic variations and to different environmental and lifestyle exposures, which resulted in some possible gene-gene and gene-environment interactions. ${ }^{13}$ However, this phenomenon needs to be further explored to find the exact mechanism behind the wide variations in the frequency of the Ala12 variant between the Caucasian and the Asian populations.

We found that the PPAR $\gamma 2$ Pro12Ala polymorphism was an independent risk factor of hypertension among Qatari's aboriginal population. Findings from our multivariable logistic regression model (adjusted for potential known confounders) revealed that the odds of hypertension were 1.69 times higher among the Ala12, as compared to the Pro12 allelic carriers. Literature regarding the association between the Pro12Ala polymorphism and hypertension is inconclusive. A study among Chinese subjects with and without myocardial infarction could not find any association, ${ }^{29}$ while, on the other hand, a study among Chinese nonagenarians/centenarians found that the Ala12 variant was associated with lower blood pressure as compared to the counterparts. ${ }^{15}$ Another study among the Swedish type II diabetic population also reported an association of the Ala12 variant with lower diastolic blood pressure among diabetic men and no association with type II diabetic women. ${ }^{17}$

Table 3 Distribution of PPAR 22 gene polymorphism across hypertensive and normotensive in Qatar $(\mathrm{N}=\mathrm{I}, 528)$

\begin{tabular}{|c|c|c|c|c|}
\hline & $\begin{array}{l}\text { Total } \\
\mathrm{N}=\mathrm{I}, 528 \text { (\%) }\end{array}$ & $\begin{array}{l}\text { Hypertensive } \\
\mathrm{N}=220 \text { (\%) }\end{array}$ & $\begin{array}{l}\text { Normotensive } \\
\mathrm{N}=1,308 \text { (\%) }\end{array}$ & $P$-value \\
\hline \multicolumn{5}{|l|}{ Genotype } \\
\hline Prol2Pro & I,360 (89.0) & $185(84.1)$ & I, I75 (89.8) & 0.003 \\
\hline Prol2Ala & $150(9.8)$ & $28(12.7)$ & $122(9.3)$ & \\
\hline $\mathrm{Ala} \mid 2 \mathrm{Ala}$ & $18(1.2)$ & $7(3.2)$ & II (0.8) & \\
\hline Prol2Pro & $\mathrm{I}, 360(89.0)$ & I85 (84.I) & I, I75 (89.8) & 0.012 \\
\hline Prol2Ala or Ala I2Ala & $168(11.0)$ & $35(15.9)$ & $133(10.2)$ & \\
\hline
\end{tabular}


Table 4 Distribution of the frequency of Prol2Ala polymorphism and alleles with obesity and hypertension in $\mathrm{Q} a t a r(\mathrm{~N}=1,528)$

\begin{tabular}{|c|c|c|c|c|}
\hline & \multicolumn{2}{|l|}{ Obesity } & \multicolumn{2}{|l|}{ Hypertension } \\
\hline & $\begin{array}{l}\text { Obese } \\
N=420 \text { (\%) }\end{array}$ & $\begin{array}{l}\text { Nonobese } \\
\mathrm{N}=1,108(\%)\end{array}$ & $\begin{array}{l}\text { Hypertensive } \\
\mathrm{N}=220 \text { (\%) }\end{array}$ & $\begin{array}{l}\text { Normotensive } \\
\mathrm{N}=\mathrm{I}, 308 \text { (\%) }\end{array}$ \\
\hline \multicolumn{5}{|l|}{ Genotype } \\
\hline Prol2Pro & $375(89.3)$ & $985(88.9)$ & $185(84.1)$ & I, $175(89.8)$ \\
\hline Prol2Ala & $39(9.3)$ & III (I0.0) & $28(12.7)$ & $122(9.3)$ \\
\hline Ala I2Ala & $6(1.4)$ & $12(1.1)$ & $7(3.2)$ & II (0.8) \\
\hline Chi-square value ( $P$-value) & $0.480(0.787)$ & & II.67 (0.003) & \\
\hline \multicolumn{5}{|l|}{ Allele frequency } \\
\hline Pro & $789(93.9)$ & $2,081(93.9)$ & $398(90.5)$ & $2,472(94.5)$ \\
\hline Ala & $5 I(6.1)$ & $135(6.1)$ & $42(9.5)$ & I 44 (5.5) \\
\hline Chi-square value ( $P$-value) & $0.004(0.983)$ & & $10.76(0.001)$ & \\
\hline OR $(95 \% \mathrm{Cl})$ & $1.00(0.7 I-1.42)$ & & $1.81(1.24-2.63)$ & \\
\hline
\end{tabular}

Abbreviations: $\mathrm{OR}$, odds ratio; $\mathrm{Cl}$, confidence interval.

On the contrary, studies among Korean women, ${ }^{16}$ the Caucasian population from the USA, ${ }^{30}$ and the obese diabetic type II patients from Poland ${ }^{31}$ found a significant association between the Ala12 variant and hypertension, which is consistent to our results. A number of limitations should be kept in mind regarding the controversial studies, such as the recruitment of the high-risk population (diabetic, myocardial infarction, and very aged [centenarians]), apparently smaller sample sizes and nonadjustment for potential confounders especially antihypertensive medications that might affect the validity of their findings. In contrast, our finding is more robust and valid, due to the sufficiently large sample size from the general population and an adjustment for potential confounders through regression analysis.

Although the exact mechanism behind the association between the Pro12Ala polymorphism and hypertension among the human population is still unknown; evidence from some preliminary studies suggested that the substitution of alanine for proline in the PPAR $\gamma$ gene results in a lower affinity of PPAR $\gamma 2$ for binding to the PPAR response elements in its target genes. ${ }^{7}$ Hence, reduced PPAR $\gamma 2$ function might be responsible for higher blood pressure. As studies have shown, PPAR $\gamma 2$ inhibits the proliferation of vascular smooth muscle

Table 5 Multivariable logistic regression analysis for association of PPAR $\gamma 2$ Ala allele with hypertension in Qatar

\begin{tabular}{llll}
\hline Variables & $\begin{array}{l}\text { Adjusted } \\
\text { odds ratio }\end{array}$ & $\mathbf{9 5 \%} \mathbf{C l}$ & $P$-value \\
\hline Ala allele & 1.69 & $\mathrm{I} .12-2.55$ & 0.012 \\
Age & $\mathrm{I} .0 \mathrm{I}$ & $0.99-\mathrm{I} .02$ & 0.339 \\
Obesity & $\mathrm{I} .67$ & $\mathrm{I} .23-2.26$ & $0.00 \mathrm{I}$ \\
Triglycerides (mmol/L) & $\mathrm{I} .18$ & $\mathrm{I} .0 \mathrm{I}-\mathrm{I} .39$ & 0.047 \\
LDL-C (mmol/L) & 0.92 & $0.78-\mathrm{I} .07$ & 0.277 \\
\hline
\end{tabular}

Note: Model adjusted for sex, smoking, physical activity, consanguinity, and use of antihypertensive medicine.

Abbreviations: $\mathrm{Cl}$, confidence interval; LDL-C, low-density lipoprotein cholesterol. cells. ${ }^{32,33}$ Therefore, it is plausible that the lower function of the PPAR $\gamma 2$ gene among the Ala12 variant will decrease/stop the inhibition of the proliferation of vascular smooth muscle cells by suppressing the expression of the matrix metallopeptidase 9 and the type 1 angiotensin II receptor, thereby resulting in higher blood pressure than the counterparts.

Our results did not reveal an association between the Pro12Ala polymorphism and obesity in Qatar's aboriginal population. The association remained nonsignificant even after an adjustment for age, sex, smoking, physical activity, and consanguinity, suggesting that the Ala12 variant is not an independent risk factor for obesity in this population. Our finding is consistent with the previous report from Qatar ${ }^{14}$ and several other countries, such as Korea, ${ }^{16}$ People's Republic of China, ${ }^{29}$ and France. ${ }^{11}$ However, a study among native Javanese in Indonesia ${ }^{12}$ and a meta-analysis using 30 independent studies ${ }^{34}$ reported obesity associated with the Ala allele. Differences in results could be attributed to different criterion (eg, BMI) to define obesity, variations in the distribution of the Ala allele, environmental and dietary factors, and a genetic background across different ethnicities. Literature also revealed gene-nutrient interaction via the PPAR $\gamma$ locus, suggesting a greater BMI in Ala carriers when the dietary polyunsaturated fat-to-saturated fat ratio

Table 6 Multivariable logistic regression analysis for association of PPAR $\gamma 2 A$ la allele with obesity in Qatar

\begin{tabular}{llll}
\hline Variables & $\begin{array}{l}\text { Adjusted } \\
\text { odds ratio }\end{array}$ & $\mathbf{9 5 \%} \mathbf{C l}$ & P-value \\
\hline Ala allele & 0.94 & $0.65-1.35$ & 0.740 \\
Age (year) & 0.99 & $0.98-1.00$ & 0.056 \\
Triglycerides (mmol/L) & 1.01 & $0.86-1.15$ & 0.943 \\
LDL-C (mmol/L) & 1.01 & $0.89-1.14$ & 0.965 \\
\hline
\end{tabular}

Note: Model adjusted for sex, smoking, physical activity, and consanguinity. Abbreviations: $\mathrm{Cl}$, confidence interval; $\mathrm{LDL}-\mathrm{C}$, low-density lipoprotein cholesterol. 
was low, and vice versa. ${ }^{35}$ Thus, the relationship between obesity and the Ala12 variant is modulated by multiple factors. Hence, it is plausible to obtain mixed results from different populations.

To elucidate the impact of consanguinity on Pro12Ala polymorphism and its association with hypertension and obesity, we included an interaction term between consanguinity and the Ala12 variant in our multivariable regression models. Although consanguinity was an independent risk factor for hypertension in the model, its interaction with an Ala12 variant was statistically insignificant in both models. This finding suggests that consanguinity did not potentiate or decrease the risk of hypertension and/or obesity among the Ala allele carriers. Literature is not available regarding the association of Pro12Ala polymorphism with obesity and hypertension among a consanguineous population. Therefore, we are the first to report no interaction between consanguinity and the Ala12 variant in terms of hypertension and obesity.

\section{Conclusion}

Our study revealed a significant association between the PPAR $\gamma 2$ Ala allele and hypertension in the highly consanguineous aboriginal Qatari population. On the other hand, we found no association between the Ala allele and obesity.

\section{Acknowledgments}

The project was supported and funded by the support of the Qatar Diabetic Association and the Qatar Foundation. We also would like to thank the Hamad Medical Corporation for its approval of this study (Hamad Medical Center Research Protocol \#10262-1027A/2011).

\section{Author Contributions}

Authors AB and SD organized the study, collected the data and revised the manuscript. Also, AB guided statistical analysis and wrote the first draft of the manuscript. MTY analyzed the data, interpreted results, and critically revised the first draft of manuscript. AOAAAH and RMM contributed to the interpretation of data and writing the manuscript.

\section{Disclosure}

The authors report no conflicts of interest in this work.

\section{References}

1. Issemann I, Green S. Activation of a member of the steroid hormone receptor superfamily by peroxisome proliferators. Nature. 1990; 347(6294):645-650.

2. Schoonjans K, Auwerx J. Thiazolidinediones: an update. Lancet. 2000;355(9208):1008-1010.
3. Spiegelman BM. PPAR-gamma: adipogenic regulator and thiazolidnedione receptor. Diabetes. 1998;47(4):507-514.

4. Beamer BA, Negri C, Yen CJ, et al. Chromosomal localization and partial genomic structure of the human peroxisome proliferator activated receptor-gamma (hPPAR gamma) gene. Biochem Biophys Res Commun. 1997;233(3):756-759.

5. Auwerx J. PPARgamma, the ultimate thrifty gene. Diabetologia. 1999; 42(9):1033-1049.

6. Yamamoto J, Kageyama S, Nemoto M, et al. PPARgamma2 pro12Ala polymorphism and insulin resistance in Japanese hypertensive patients. Hypertens Res. 2002;25(1):25-29.

7. Tamori Y, Masugi J, Nishino N, Kasuga M. Role of peroxisome proliferator-activated receptor-gamma in maintenance of the characteristics of mature 3T3-L1 adipocytes. Diabetes. 2002;51(7): 2045-2055.

8. Barroso I, Gurnell M, Crowley VE, et al. Dominant negative mutations in human PPARgamma associated with severe insulin resistance, diabetes mellitus and hypertension. Nature. 1999;402(6764): 880-883.

9. Sharma AM, Staels B. Review: Peroxisome proliferator-activated receptor gamma and adipose tissue - understanding obesity-related changes in regulation of lipid and glucose metabolism. J Clin Endocrinol Metab. 2007;92(2):386-395.

10. Stumvoll M, Häring $H$. The peroxisome proliferator-activated receptor-gamma2 Pro12Ala polymorphism. Diabetes. 2002;51(8): 2341-2347.

11. Ghoussaini M, Meyre D, Lobbens S, et al. Implication of the Pro12Ala polymorphism of the PPAR-gamma 2 gene in type 2 diabetes and obesity in the French population. BMC Med Genet. 2005;6:11.

12. Danawati $\mathrm{CW}$, Nagata $\mathrm{M}$, Moriyama $\mathrm{H}$, et al. A possible association of Pro12Ala polymorphism in peroxisome proliferators-activated receptor gamma2 gene with obesity in native Javanese in Indonesia. Diabetes Metab Res Rev. 2005;21(5):465-469.

13. Passaro A, Dalla Nora E, Marcello C, et al. PPAR $\gamma$ Pro12Ala and ACE ID polymorphisms are associated with BMI and fat distribution, but not metabolic syndrome. Cardiovasc Diabetol. 2011;10:112.

14. Badii R, Bener A, Zirie M, et al. Lack of association between the Pro12Ala polymorphism of the PPAR-gamma 2 gene and type 2 diabetes mellitus in the Qatari consanguineous population. Acta Diabetol. 2008;45(1):15-21.

15. Lu Z, Dong B, Mo X, et al. Pro12Ala polymorphism in PPAR gamma 2 associated with essential hypertension in Chinese nonagenarians/centenarians. Exp Gerontol. 2008;43(12):1108-1113.

16. Kim K, Lee S, Valentine RJ. Association of pro12Ala polymorphism in the peroxisome proliferative-activated receptor gamma2 gene with obesity and hypertension in Korean women. J Nutr Sci Vitaminol (Tokyo). 2007;53(3):239-246.

17. Ostgren CJ, Lindblad U, Melander O, Melander A, Groop L, Råstam L. Peroxisome proliferator-activated receptor-gammaPro12Ala polymorphism and the association with blood pressure in type 2 diabetes: skaraborg hypertension and diabetes project. J Hypertens. 2003;21(9): 1657-1662.

18. Bener A, Alali KA. Consanguineous marriages in the new developed country: the Qatari population. J Biosoc Sci. 2006;38(2):239-246.

19. Sandridge AL, Takeddin J, Al-Kaabi E, Frances Y. Consanguinity in Qatar: knowledge, attitude and practice in a population born between 1946 and 1991. J Biosoc Sci. 2010;42(1):59-82.

20. Hunter-Zinck H, Musharoff S, Salit J, et al. Population genetic structure of the people of Qatar. Am J Hum Genet. 2010;87(1):17-25.

21. Bener A, Al-Suwaidi J, Al-Jaber K, Al-Marri S, Elbagi IE. Epidemiology of hypertension and its associated risk factors in the Qatari population. J Hum Hypertens. 2004;18(7):529-530.

22. Bener A. Prevalence of obesity, overweight, and underweight in Qatari adolescents. Food Nutr Bull. 2006;27(1):39-45.

23. Bener A, Yousafzai MT, Darwish S et al. Obesity index that better predict Metabolic Syndrome: Body Mass Index, Waist Circumference, Waist Hip Ratio, or Waist Height Ratio. Journal of Obesity. 2013. Available from: http:/www.hindawi.com/journals/jobes/2013/269038/. 
24. World Health Organization. Obesity: Preventing and Managing the Global Epidemic. Report of a WHO Consultation on Obesity. Geneva: World Health Organization; 1997. Available from: http://whqlibdoc. who.int/hq/1998/WHO_NUT_NCD_98.1_\%28p1-158\%29.pdf. Accessed June 10, 2013.

25. Chobanian AV, Bakris GL, Black HR, et al; National Heart, Lung, and Blood Institute Joint National Committee on Prevention, Detection, Evaluation, and Treatment of High Blood Pressure; National High Blood Pressure Education Program Coordinating Committee. The Seventh Report of the Joint National Committee on Prevention, Detection, Evaluation, and Treatment of High Blood Pressure: the JNC 7 report. JAMA. 2003;289(19):2560-2572.

26. Beamer BA, Yen CJ, Andersen RE, et al. Association of the Pro12Ala variant in the peroxisome proliferator-activated receptorgamma2 gene with obesity in two Caucasian populations. Diabetes. 1998;47(11):1806-1808.

27. Mori H, Ikegami H, Kawaguchi Y, et al. The Prol2 -->Ala substitution in PPAR-gamma is associated with resistance to development of diabetes in the general population: possible involvement in impairment of insulin secretion in individuals with type 2 diabetes. Diabetes. 2001;50(4):891-894.

28. Lei HH, Chen MH, Yang WS, et al. Peroxisome proliferator-activated receptor gamma 2 Pro12Ala gene variant is strongly associated with larger body mass in the Taiwanese. Metabolism. 2000;49(10):1267-1270.

29. Wang LP, Zhao LR, Cui HW, Yan MR, Yang L, Su XL. Association between PPAR $\gamma 2$ Pro12Ala polymorphism and myocardial infarction and obesity in Han Chinese in Hohhot, China. Genet Mol Res. 2012;11(3):2929-2938.
30. Hasstedt SJ, Ren QF, Teng K, Elbein SC. Effect of the peroxisome proliferator-activated receptor-gamma 2 pro(12)ala variant on obesity, glucose homeostasis, and blood pressure in members of familial type 2 diabetic kindreds. J Clin Endocrinol Metab. 2001;86(2): 536-541.

31. Stefański A, Majkowska L, Ciechanowicz A, et al. Association between the Pro12Ala variant of the peroxisome proliferator-activated receptor-gamma2 gene and increased 24-h diastolic blood pressure in obese patients with type II diabetes. J Hum Hypertens. 2006;20(9): 684-692.

32. Ji Y, Liu J, Wang Z, Liu N, Gou W. PPARgamma agonist, rosiglitazone, regulates angiotensin II-induced vascular inflammation through the TLR4-dependent signaling pathway. Lab Invest. 2009;89(8): 887-902.

33. Sugawara A, Takeuchi K, Uruno A, et al. Transcriptional suppression of type 1 angiotensin II receptor gene expression by peroxisome proliferator-activated receptor-gamma in vascular smooth muscle cells. Endocrinology. 2001;142(7):3125-3134.

34. Masud S, Ye S; SAS Group. Effect of the peroxisome proliferator activated receptor-gamma gene Pro12Ala variant on body mass index: a meta-analysis. J Med Genet. 2003;40(10):773-780.

35. Luan J, Browne PO, Harding AH, et al. Evidence for gene-nutrient interaction at the PPAR $\gamma$ locus. Diabetes. 2001;50(3):686-689.
The Application of Clinical Genetics

\section{Publish your work in this journal}

The Application of Clinical Genetics is an international, peer-reviewed open access journal that welcomes laboratory and clinical findings in the field of human genetics. Specific topics include: Population genetics; Functional genetics; Natural history of genetic disease; Management of genetic disease; Mechanisms of genetic disease; Counseling and ethical

\section{Dovepress}

issues; Animal models; Pharmacogenetics; Prenatal diagnosis; Dysmorphology. The manuscript management system is completely online and includes a very quick and fair peer-review system, which is all easy to use. Visit http://www.dovepress.com/testimonials.php to read real quotes from published authors 